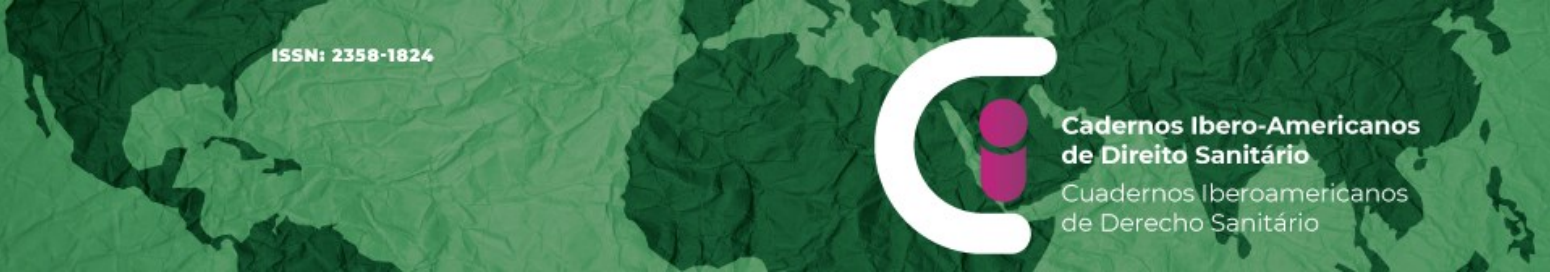

\title{
Educar para la salud en tiempos de pandemia
}

Health education in times of pandemic

Educar para a saúde em tempos de pandemia

Vicente Bellver Capella ${ }^{1}$

\section{Resumen}

La experiencia de la pandemia que estamos viviendo exige repensar la educación para la salud. En este trabajo lo hacemos a partir de dos conceptos procedentes de la Declaración Universal de los Derecho Humanos: primero, entender que el fin de la educación es el pleno desarrollo de la persona; y segundo, que los deberes para con la comunidad contribuyen a ese desarrollo. A partir de ellos, defendemos una concepción de la educación para la salud basada en el carácter relacional del ser humano, en la relevancia de los determinantes sociales de la salud y en los peligros del entorno digital, a pesar de los enormes beneficios que ha aportado durante la pandemia.

\section{Palabras clave}

Pandemia. Educación en Salud. Ética.

\section{Abstract}

The experience of the pandemic that we are living requires rethinking health education. In this paper we do it based on two ideas from the Universal Declaration of Human Rights: first, that the aim of education is the full development of the person; and second, that duties towards the community contribute to that development. Based on them, we defend a conception of health education based on the relational nature of the human being, on the relevance of the social determinants of health and on the dangers of the digital environment, despite the enormous benefits it has brought during the pandemic.

\section{Keywords}

Pandemic. Health Education. Ethics.

\section{Resumo}

A experiência da pandemia que vivemos exige repensar a educação em saúde. Neste trabalho, fazemo-lo com base em dois conceitos da Declaração Universal dos Direitos do Homem: primeiro, compreender que o objetivo da educação é o desenvolvimento integral da pessoa; e segundo, que os deveres para com a comunidade contribuem para esse desenvolvimento. A partir deles, defendemos uma conceção de educação em saúde baseada na natureza relacional do ser humano, na relevância dos determinantes sociais da saúde e nos perigos do meio digital, apesar dos enormes benefícios que trouxe.

\section{Palavras-chave}

Pandemia. Educação para a saúde. Ética.

\footnotetext{
${ }^{1}$ Catedrático de Filosofía del Derecho, Departamento de Filosofía del Derecho y Política, Universitat de València, València, España. https://orcid.org/0000-0002-8776-397X. E-mail: Vicente.Bellver@uv.es
} 


\section{Introducción}

Con demasiada frecuencia se contempla la educación como el recurso capaz de resolver todos los problemas y lograr las metas de la humanidad. Así, hablamos de educación como medio para alcanzar la paz, la democracia, la ciudadanía, la sostenibilidad, el medio ambiente, los derechos humanos... y también de educación para la salud. Sin duda la educación tiene una enorme capacidad de mejora de la vida de las personas y las sociedades. Pero es un error pensar que la educación es la clave para solucionar todos los problemas de la humanidad: cuando lo hacemos, creamos unas expectativas desmesuradas sobre su potencial que únicamente conducen a experimentos educativos fallidos que disparan la frustración.

A día de hoy nadie duda de que la educación en general, y la alfabetización y educación en salud en particular ${ }^{2}$, es uno de los determinantes sociales de la salud. Una población educada y con un buen nivel de conocimientos sobre la salud tendrá una mayor esperanza de vida, padecerá menos enfermedades, disfrutará de un mayor bienestar y podrá desarrollar vidas más plenas. Como también es de sobra conocido, esa convicción se consagró en las políticas públicas de salud a nivel mundial con la Declaración de Alma Ata sobre Atención Primaria (1978) y en la Carta de Ottawa sobre promoción de la salud (1986), en la que se afirmó: "Las condiciones y requisitos para la salud son: la paz, la educación, la vivienda, la alimentación, la renta, un ecosistema estable, la justica social y la equidad" (2).

Como en tantos otros campos, la educación para la promoción de la salud y la prevención de la enfermedad (que resumidamente denominaremos Educación para la Salud (EpS) no estaba preparada para un contexto de pandemia como el que estamos sufriendo. Es comprensible que así sea pues la última gran pandemia que sufrió la humanidad fue a principios del siglo $\mathrm{XX}$, cuando todavía no se habían desarrollado las políticas de salud pública de alcance global. Es cierto que algunos autores llevan advirtiendo desde hace años del riesgo de una pandemia como la que sufrimos ahora. Pero esas advertencias no se tomaron en serio, entre otras razones porque las pandemias que se han desencadenado en

\footnotetext{
${ }^{2}$ El término inglés health literacy, que en la Declaración de Astaná (2018) de la Conferencia Mundial sobre Asistencia Primaria y en otros documentos se ha sido traducido al español como educación sobre la salud, en otros textos ha sido traducido como conocimientos sanitarios (por ejemplo, en la Declaración de Shanghai sobre la Promoción de la Salud en la Agenda 2030 para el Desarrollo Sostenible, aprobada en la 9a Conferencia Global de Promoción de la Salud, 2016) o como alfabetización en salud, que es el empleado por la OMS para la traducción oficial de health literacy. Precisamente la OMS define este concepto de albafetización en salud como "las habilidades cognitivas y sociales que determinan la motivación y la capacidad de los individuos para acceder a la información, comprenderla y utilizarla, para promover y mantener una buena salud" (1, p.21). Habida cuenta de la diversidad de traducciones de la que ha sido objeto el término health literacy, y que el objetivo aquí no es analizar las diferencias entre alfabetización y educación en salud, voy a entenderlos ambos en sentido análogo.
} 
las últimas décadas se han podido controlar con celeridad y han tenido un alcance limitado. Es de esperar que, en los próximos años, se revisen los modelos de EpS, de manera que incorporen las enseñanzas que nos está dejando la actual pandemia. Sin duda, los determinantes sociales de salud y la asistencia primaria seguirán siendo los pilares para conseguir la equidad en salud. Pero resulta imperioso comprenderlos desde la perspectiva sobre el ser humano y la salud que nos proporciona la pandemia. En las siguientes páginas mencionaré brevemente algunos problemas relacionados con la EpS que se han suscitado durante la pandemia y sobre los que deberíamos reflexionar sosegadamente para introducir algunos cambios importantes.

La EpS debe transitar entre dos graves riesgos: en un extremo, tratar de imponer a los ciudadanos una concepción integral sobre la salud, que cercene la libertad de las personas y las comunidades; en el otro, dejar que sea el mercado quien eduque en materia de salud. Caer en alguno de estos dos extremos sería desastroso para manejar una pandemia como la actual y, en general, para "Garantizar una vida sana y promover el bienestar de todos a todas las edades", como dice el ODS 3 (3). Para identificar un concepto de EpS que realmente contribuya a mejorar la salud de las personas sin recortar sus derechos ni abandonarlas a las presiones del mercado, resulta muy orientadora la visión sobre la educación contenida en la Declaración Universal de Derechos Humanos (DUDH) (4).

\section{Los fines de la educación}

El art. 26 de la DUDH proclama el derecho a la educación y establece que "la educación tendrá por objeto el pleno desarrollo de la personalidad humana y el fortalecimiento del respeto a los derechos humanos y a las libertades fundamentales" (4). La educación, por tanto, no solo va dirigida al desarrollo del individuo sino al fortalecimiento de los derechos humanos. Y lo más interesante es que no plantea estos dos fines en conflicto sino como complementarios. Así se ve a la luz del art. 29, que dice "1. Toda persona tiene deberes respecto a la comunidad, puesto que sólo en ella puede desarrollar libre y plenamente su personalidad" (4). Es decir, que la persona que cumple con sus deberes con la comunidad, entre los que indudablemente está el respeto de los derechos humanos, contribuye a crear las condiciones para alcanzar el pleno desarrollo de su propia personalidad (5). 
Por tanto, educar no es solo instruir. Es promover las capacidades que permiten a todo ser humano tener una vida plena. La educación enseña a leer y a contar, a pensar críticamente y a analizar con rigor un campo de la realidad. Pero esas capacidades instrumentales se orientan, a su vez, al logro del fin último de la educación: aprender a pensar sobre el sentido de la existencia y a relacionarse con uno mismo, con los demás y con el mundo.

Para alcanzar ese pleno desarrollo de la personalidad, la educación debe fortalecer en cada ser humano el respeto de los derechos humanos y el cumplimiento de los deberes para con la comunidad. Esto se concreta en tres exigencias: educar a los estudiantes en el conocimiento de los derechos humanos; educarles de acuerdo con los derechos humanos; y educarles para que respeten y promuevan los derechos humanos. El requisito para que estas tres exigencias puedan cumplirse es la existencia de un marco social y político que reconozca los derechos humanos.

Traslademos lo dicho con carácter general sobre la educación al campo de la EpS. La EpS debe orientarse al pleno desarrollo de la personalidad. Por tanto, su fin no es solo procurar unos parámetros biológicos óptimos para prolongar la vida humana sino poner a las personas en condiciones de construir un relato significativo de su vida. Eso supone proveerles de ciertos conocimientos sobre cuidado de la salud, y exigirles el cumplimiento de los deberes de autocuidado y protección de la salud de los otros. Ahora bien, el requisito para que esa EpS alcance sus objetivos será garantizar un marco social y político idóneo, lo que desde las conferencias de Alma Ata (1978), y sobre todo Ottawa (1986) (2) y Adelaida (1988) conocemos como determinantes sociales de salud. Pero antes de referirme a dichos determinantes conviene aclarar dos cuestiones sobre la educación: ¿dónde se educa? ¿y quiénes educan?

\section{La educación para la salud (EpS): entornos y agentes}

A grandes rasgos, existen tres niveles de educación: formal, no formal e informal. El primero abarca el itinerario educativo oficial, integrado por la enseñanza primaria, secundaria y superior; el segundo abarca el conjunto de actividades educativas más o menos oficiales que, sin embargo, no forman parte de la educación formal; y el tercero incluye a todos los agentes que, aun estando fuera de los sistemas anteriores, ejercen un impacto educativo relevante en la sociedad. Pues bien, aunque lo deseable sería que la escuela (nivel 1), junto con los diversos agentes del sistema de salud (nivel 2), que abarca desde los sanitarios de 
atención primaria que tratan directamente con las personas hasta las campañas de salud pública, fueran los principales educadores, lo cierto es que son los medios de comunicación y, sobre todo, internet y las redes sociales (nivel 3), los protagonistas de la EpS de los ciudadanos. De hecho, para conseguir que determinadas medidas de protección durante la pandemia fueran adoptadas por la población, en determinados países se optó por recurrir a que algunos influencers utilizaran sus canales para lanzar determinados mensajes.

El protagonismo del entorno digital en el campo de educativo durante la pandemia se ha exacerbado. No me refiero a la conversión, de la noche a la mañana, de los sistemas educativos presenciales en virtuales, con todos los efectos colaterales que ello está teniendo sobre la salud y la socialización de los niños, y más aún sobre aquellos que carecían de recursos (conexión y dispositivos) para continuar las clases online. Me refiero, en este momento, al fenómeno de la infodemia, que ha traído consigo efectos casi tan negativos para la sociedad como la propia pandemia. Esa suerte de bulimia informativa se ha convertido en el principal recurso cognitivo para muchos sobre la pandemia y cómo reaccionar ante ella. A ello ha influido sin duda la migración que todos hemos hecho del mundo analógico al digital. Más adelante me ocuparé de estos dos fenómenos: la infodemia y la progresiva desconexión del mundo analógico para habitar cada vez más tiempo en el entorno digital.

Los tres entornos mencionados (formal, no formal e informal) cuentan con un agente principal: la escuela y la universidad son los agentes principales de la educación formal; los profesionales de la salud, los de la educación no formal; y el infinito universo informativo y relacional del entorno digital, el de la educación informal. Cada uno de ellos educa, pero, para poderlo hacer, tiene a su vez que ser educado. Los profesionales sanitarios suelen tener acceso a una formación reglada para desempeñar su responsabilidad como educadores para la salud. Ello no quiere decir que esa formación cuente con todas las garantías, como se verá más adelante. Salvo aquellos que imparten materias directamente relacionadas con EpS, no es seguro que los profesores de la educación formal tengan la preparación para conseguir que la EpS se convierta en un elemento transversal del curriculum formativo. En países como España ni siquiera se ha normalizado la figura de la enfermera escolar (6). Por último, el agente que más influye de forma positiva o negativa en la EpS, como es el entorno digital, carece de cualquier mecanismo de supervisión o control. La consecuencia es evidente: no está garantiza la educación de los educadores en salud y 
el agente (des)educador más influyente está, de hecho, al margen de cualquier orientación o supervisión.

\section{La salud está condicionada por determinantes sociales}

Aunque se insiste desde hace casi medio siglo en el carácter social de la salud, la pandemia ha hecho que todos lo comprobemos de forma dramática y en primera persona. Es cierto que la edad ha sido, con diferencia, el factor de riesgo principal con respecto a la letalidad del contagio. Podría parecer, entonces, que ha sido un factor puramente biológico el que ha determinado el impacto de la COVID-19 en la población. Esa visión es errónea porque no incluye el papel completamente determinante de los factores sociales. En primer lugar, los fallecimientos por el virus SARS-CoV-2 se han cebado principalmente en las residencias de personas mayores. Se ha puesto, así, de manifiesto que esas personas no contaban con un entorno de vida que les protegiera de su frágil condición. Al contrario, vivir en una residencia los exponía a graves riesgos, como la infección por el virus puso flagrantemente de manifiesto. La variable biológica de la edad, unida a la variable social de vivir en unas residencias que no contaban con sistemas sociosanitarios adecuados, ha sido el binomio mortal en esta pandemia. Como se verá más adelante, la respuesta sanitaria inicial a este desafío fue un completo desatino. A muchas de estas personas se las abandonó a su suerte, por entender que su vida valía menos que las de personas más jóvenes. Afortunadamente, los criterios adoptados para la administración de vacunas están siendo muy distintos de los que se adoptaron para decidir sobre los ingresos a las unidades de cuidados intensivos (UCls) y la asignación de respiradores. Así se ha podido reparar parcialmente el error garrafal de la primera ola de la pandemia.

Pero si vivir en una residencia constituía el mayor riesgo de fallecimiento por COVID19, sin duda el código postal de las personas ha determinado en buena medida el riesgo de contagio entre la población en general. Las personas que no pueden teletrabajar por el tipo de trabajo que desempeñan; que no pueden realizarse pruebas de detección de la enfermedad por falta de acceso a recursos sanitarios; que no pueden dejar de trabajar, aunque estén infectadas, por temor a perder un trabajo en el que les va la vida; que no pueden dejar de salir de casa porque no tienen a nadie que les asista ... en definitiva, las personas que tienen una situación socio-laboral precaria y, consecuentemente, unos niveles de renta bajos, son las más expuestas a contagiarse. Este riesgo se ve agravado en las personas reclusas o internadas en centros de internamiento para emigrantes, es decir, en 
aquellas personas que tienen una relación de especial sujeción a la administración pública. Es lamentable que las personas que deberían tener más protegida su salud, por estar tuteladas por los poderes públicos, estén entre las más expuestas al contagio (7).

Pero el problema no es solo que los más vulnerables son los más expuestos al contagio. También son los que menos posibilidades tienen de: recibir asistencia (sobre todo en los países que carecen de cobertura universal); mantener el trabajo; continuar con la educación online para sus hijos; sobrellevar el confinamiento por las graves carencias de las viviendas que habitan, etc. De forma trágica la pandemia ha vuelto a confirmar que el riesgo de enfermar, y el impacto de la enfermedad sobre la vida de las personas, está asociado a los determinantes sociales de salud.

La EpS exige en primer lugar educar a los responsables de las políticas de salud para que adopten políticas integrales de salud, que protejan a los grupos humanos más vulnerables. Y si esa protección preventiva no se consigue, al menos habrá que garantizar un acceso equitativo a los recursos sociosanitarios en las situaciones de enfermedad, cosa que tampoco se consiguió en la primera ola de la pandemia, cuando los mayores de las residencias quedaron desatendidos.

\section{La salud, un bien individual y colectivo, un derecho y deber}

La pandemia actual nos hace comprender que la protección individual de la salud es un bien que está, en buena medida, en manos de los demás. Para que sigamos adelante con nuestros planes de vida, todos debemos cumplir con unas medidas que son una protección para nosotros y para con la comunidad. Por eso, no son solo una opción personal sino un auténtico deber para la comunidad. Cuando cumplimos con la comunidad, tal como nos exige el art. 29 de la Declaración Universal de Derechos Humanos (4), no solo evitamos el contagio de personas concretas sino también conseguimos que se levanten las medidas limitativas de derechos (confinamientos, toques de queda, cierres perimetrales, o restricciones en determinados sectores de la actividad económica, social o cultural) que obstruyen temporalmente nuestro pleno desarrollo. En definitiva, cumplir con la comunidad posibilita nuestro desarrollo personal.

La pandemia debería servir para reafirmar, más aún si cabe, que uno de los presupuestos de la EpS es reconocer en la salud un bien tanto individual como colectivo. $Y$ así es porque cuando una comunidad disfruta de condiciones ambientales adecuadas, espacios idóneos para el esparcimiento y el encuentro comunitario, saneamiento, acceso a 
agua potable y alimentos sanos, seguridad energética y atención primaria próxima, todas las personas mejoran en su salud. La mejora colectiva redunda en la mejora individual.

Precisamente porque no es solo un bien individual sino también colectivo, la protección de la salud no es solo un derecho sino también un deber. De nuevo la pandemia nos permite comprobarlo a diario. Si cuido las medidas para evitar contagios y contagiar, si no difundo bulos ni contribuyo a crear un clima de crispación, si velo para que la limitación en el ejercicio de los derechos por causa de la pandemia sea proporcional al riesgo que se pretende combatir, si me vacuno cuando me corresponda, estaré cumpliendo con unos deberes cívicos que son, a su vez, garantía de mi derecho a la protección de la salud.

El reconocimiento de que la salud sea un deber no quiere decir que su cumplimiento tenga necesariamente que exigirse bajo coacción. El caso de la vacunación es paradigmático: en la mayor parte de los países del mundo los ciudadanos no tienen una obligación legal de vacunarse, pero eso no quiere decir que no tengan la obligación cívica de hacerlo (8). Vacunarse frente a la COVID-19 no es solo un derecho sino también un deber, aunque no se exija coactivamente. Ni la vacuna es voluntaria, ni existe el derecho a no vacunarse, aunque no se castigue a quien no lo haga. Esa actitud de rechazo a la vacuna es, en principio, una actitud parasitaria poco cívica (9). Es parasitaria porque permite a quienes rechazan la vacuna beneficiarse de la inmunidad de grupo (herd immunity), que se consigue a partir de un determinado porcentaje de población vacunada, sin tener que contribuir a su logro. Y es poco cívica porque su falta de contribución puede llegar a poner en una situación de desprotección a las personas en las que la vacuna no ha hecho efecto o a las que están inmunodeprimidas y no se pueden vacunar.

La idea de que la salud es un deber se manifiesta también en el cumplimiento de determinadas medidas no farmacéuticas dirigidas a evitar el contagio y la expansión de la pandemia, a las que todos nos tenemos que sujetar. Es cierto que muchas de esas medidas son exigidas bajo sanción, pero otras no. Y, sin embargo, estas medidas voluntarias, sustentadas en la autonomía personal y no en la presencia policial, suelen ser tanto o más eficaces que las coactivas porque estimulan el sentido del deber cívico (10). Por tanto, el primer objetivo de la EpS debería ser el fomento de una sólida educación ciudadana general, que persuada de que la consecución del bien común, del que la salud pública forma parte esencial, es un objetivo prioritario para conseguir también el bien personal.

En el mismo campo de las vacunas encontramos otra manifestación de cómo la protección de la salud se concibe como un deber cívico y no solo como un derecho. En el 
momento de publicarse este trabajo muchos países del mundo están administrando la vacuna frente a la COVID-19 a su población. Pero, al no haber todavía vacunas para todos y resultar en todo caso imposible vacunar a todos simultáneamente, resulta imprescindible establecer una priorización en la vacunación. Con carácter general los ciudadanos aceptan que la vacuna quede fuera del tráfico comercial ordinario y sea tratada como un bien esencial para todos, que el Estado compra en exclusiva y distribuye con criterios de justicia. En base al principio de solidaridad tenemos el deber de esperar a que llegue nuestro turno para vacunarnos.

Ahora bien, cuando hablamos de protección de la salud en tiempos de pandemia debemos entender que el principio de solidaridad trasciende el plano nacional y se extiende a nivel universal. Existen dos razones para proyectar a escala universal el principio de solidaridad con relación al acceso a la vacuna, la primera de carácter utilitario y la segunda altruista. En primer lugar, resulta obvio que la pandemia seguirá siendo una amenaza y exigirá adoptar medidas de protección mientras no se acabe con ella en todo el mundo. En consecuencia, nuestra protección pasa por universalizar el acceso a la vacuna. En segundo lugar, si aceptamos que todos los seres humanos somos iguales y que la salud es un bien universal, no podremos conformarnos con que la vacuna llegue a nuestros connacionales: debemos empeñarnos en que llegue cuanto antes también a todas las personas del mundo. La iniciativa COVAX va en esa dirección. Pero cabe preguntarse si esa medida es suficiente o deberían adoptarse otras más exigentes: ¿es justo que vacunemos en nuestro país a personas que, por su edad, no tienen un alto riesgo de morir o enfermar gravemente, mientras en otros países los profesionales sanitarios que combaten directamente la pandemia y las personas mayores de ochenta años no tienen expectativa alguna de ser vacunadas por el momento?

\section{EpS y justicia distributiva: solidaridad local y universal}

Siguiendo en este campo de la vacunación, la justa distribución de la vacuna obliga tanto a establecer los principios que deben regir la priorización en la administración de las vacunas como a darlos a conocer con trasparencia a los ciudadanos, explicando su justificación. En España concretamente se ha aprobado una estrategia de vacunación (que es objeto de actualizaciones periódicas), construida a partir de un marco ético en el que se proclaman siete principios sustantivos y cuatro procedimentales. De los siete primeros destacan tres: (1) el principio de necesidad, que se considera el idóneo para distribuir un 
recurso esencial para la salud, como es la vacuna contra la COVID-19; (2) el principio de equidad, que exige tener en cuenta las vulnerabilidades, desigualdades, riesgos y necesidades de los grupos a la hora de priorizar en el acceso a la vacuna; y (3) el principio de reciprocidad, que justifica la protección especial a los profesionales sanitarios directamente dedicados a salvaguardar la salud de los demás frente a la COVID-19. De entre los principios procedimentales, es oportuno destacar en este contexto precisamente el principio de Información y educación. Se entiende que para que los ciudadanos puedan participar en las políticas relacionadas con la salud necesitan de una información fiable y comprensible, así como de una educación básica en materia de salud. En esa educación se subrayará la importancia de las vacunas para la salud pública, así como la justificación de los criterios de priorización en el acceso a las vacunas que inmunizan frente a la COVID-19 mientras su disponibilidad sea insuficiente para atender a toda la población. A su vez, las personas que se vayan vacunando tienen el derecho a recibir con antelación información sobre la vacuna, en las mismas condiciones en las que se hace cuando se administra cualquier otra vacuna. Esa información se presentará en formatos adecuados y siguiendo el principio del diseño para todos, de manera que resulte accesible y comprensible a las personas con discapacidad (11).

Pero el principio de solidaridad no solo se proyecta en las estrategias de vacunación. Igualmente lo hace en un campo tan fundamental como es el uso secundario de los datos de salud con fines de investigación. Gracias a esos datos personales de salud se sigue avanzando en vacunas, se pueden desarrollar terapias, y se pueden prevenir futuras pandemias o combatirlas de forma más eficaz.

Existe un debate trascendental en curso acerca de la propiedad de los datos personales en general, y de los datos de salud en particular. En principio, pertenecen a las personas, pero también constituyen un bien común de la humanidad, puesto que solo con el acceso a ellos se pueden obtener progresos esenciales en muchos campos relacionados con la salud. De acuerdo con el Comité de Bioética de España puede afirmarse que seguir manteniendo el postulado de que la enfermedad y los datos que genera su tratamiento sólo pertenecen a quienes la sufren no es solo ignorar la realidad, sino también desconocer la existencia de unos valores y derechos en conflicto, y el modo correcto en que deben conciliarse. La protección de datos no es, ni nunca ha sido, un fin en sí misma, sino que, más bien, sirve para proteger a la persona en su intimidad, tanto en su esfera privada como en la esfera pública. Ahora bien, ese derecho a la intimidad, como los demás derechos, se 
manifiesta en un entorno social de interrelaciones, en el que es tan relevante reconocer la autonomía del individuo como la solidaridad del ciudadano (12).

En principio, el acceso a los datos de salud con fines de investigación solo es posible con el consentimiento del sujeto fuente. Pero en determinadas circunstancias y para ciertos objetivos de gran interés social, como por ejemplo cuando se trata de desarrollar una vacuna o un tratamiento para combatir la COVID-19, podría aprobarse el acceso a los datos de salud sin tener que solicitar el consentimiento, siempre que los datos sean debidamente pseudonimizados. En situaciones muy especiales y completamente justificadas, podría incluso permitirse el acceso a esos datos sin pseudonimizarlos. Estas tres posibilidades tienen amparo legal en la regulación europea de protección de datos de 2016.

\section{Entorno digital, infodemia y EpS}

El entorno digital ha colonizado muchas esferas de nuestra vida durante la pandemia. No solo nuestras relaciones con los seres queridos o el ocio se han canalizado en buena medida a través de las tecnologías digitales sino también nuestros mismos trabajos y hasta la asistencia sanitaria que hemos recibido (13). Si no hubiera sido por el acelerado crecimiento del entorno digital la pandemia estaría arruinando nuestra vida de una forma mucho más feroz de como lo está haciendo en este momento. Sin embargo, también intuimos que esa vida en el entorno digital es, en el mejor de los casos, un sucedáneo de la verdadera vida. Ese entorno, si bien nos mantiene conectados, nos aísla y nos hace más individualistas y narcisistas. Nos produce desasosiego porque nos aparta del mundo real; pero, al mismo tiempo, nos incapacita para volver a ese mundo real, porque es mucho más fatigoso que el digital. Si la soledad era ya uno de los problemas de salud pública más graves del presente, la migración masiva de la humanidad al universo digital como consecuencia de la pandemia no ha hecho más que incrementarlo. Las consecuencias para la salud, y para la salud mental en concreto, son devastadoras.

Al mismo tiempo que pandemia provocada el virus SARS-CoV-2, una auténtica infodemia se ha extendido por todo el mundo. La OMS la define como "una sobreabundancia de información, en línea o en otros formatos, e incluye los intentos deliberados por difundir información errónea para socavar la respuesta de salud pública y promover otros intereses de determinados grupos o personas". Hemos asistido entre atónitos e indignados a la proliferación de bulos: que la pandemia no existía, que la mascarilla no prevenía el contagio, que un determinado grupo social era el principal agente de expansión del virus, que la 
vacuna era insegura, etc. La difusión de esas falsas informaciones puede perjudicar la salud física y mental de las personas, incrementar la estigmatización de algunos grupos humanos, amenazar valiosos logros conseguidos en materia de salud y espolear al incumplimiento de las medidas de salud pública. En definitiva, la infodemia pone en peligro la capacidad de los países de frenar la pandemia y crea un ambiente tóxico para la convivencia (14).

Ante un desafío como esta infodemia, la EpS exige actuar tanto en el mundo real como en el digital. En el mundo real las autoridades públicas tienen un grave deber de trasparencia en la información. Si no se cumple con él de forma ejemplar, es inevitable que las informaciones falsas, en lugar de desacreditarse, adquieran visos de legitimidad. Cuando en ocasiones las autoridades han tratado de maquillar los datos sobre el número de fallecidos por COVID-19, no solo se ha faltado al derecho a la información sino que se ha dado alas a la infodemia (15) y a sus nefastos efectos para la salud física y mental de los ciudadanos. Los responsables políticos deben compartir una educación política, que es también una EpS, y actuar en consecuencia.

Pero tiene más trascendencia la intervención pública en el entorno digital. Se trataría de configurarlo de modo que no sea pernicioso para la salud humana. El primer recurso en que se piensa para conseguirlo es el establecimiento de controles para evitar la difusión de la desinformación: o bien por parte de las propias plataformas o bien directamente desde el poder público. Cualquiera de las dos opciones resulta muy arriesgada por lo que supone de legitimación de la censura. La clave quizá no esté tanto en controlar los contenidos como, sobre todo, en promover un diseño de las redes sociales y del entorno digital en su conjunto que estimule el pensamiento crítico y sosegado, sostenido sobre informaciones plurales y contrastadas, en lugar de una emotividad exaltada nutrida mediante el filtro burbuja (16). Si tomamos conciencia de que "las experiencias que atesoramos a cada momento, nuestras interacciones sociales, el cariz de nuestros pensamientos y nuestros hábitos cotidianos se configuran hoy, en gran medida, a partir del funcionamiento de estos ingenios" (17) entenderemos de inmediato que la clave del futuro de la humanidad, también en términos de salud, está en el diseño del entorno digital (18). Eso no es directamente EpS, pero es crear las condiciones imprescindibles para que el entorno digital, sin duda el principal (des)educador, sea menos nocivo para la salud de lo que lo es en la actualidad.

Hablando de entorno digital no se puede omitir la referencia a todos los instrumentos que se han desarrollado desde el inicio de la pandemia para prevenir los contagios y seguir el rastro de la enfermedad. También aquí comparece el riesgo de colisión entre dos bienes 
humanos fundamentales: la protección de la salud pública y la salvaguardia del derecho a la intimidad y la no discriminación. Se ha dicho con razón que los países del este asiático han primado el interés colectivo sobre el del individuo (19) mientras que Europa ha tratado de conciliar sin éxito los dos. La EpS debería contribuir al logro de esa conciliación. ¿De qué sirve salvaguardar la intimidad si el precio es perder la vida? Pero ¿de qué sirve salvaguardar la vida si es a costa de renunciar a la intimidad? Profesionales de la salud, las tecnologías digitales y el Derecho deben ser capaces de encontrar cursos de acción intermedios que no menoscaben ninguno de esos bienes y pongan a la persona en el centro.

\section{Formar al formador: la EpS de los profesionales de la salud.}

Como no podía ser de otra manera, los profesionales de la salud están siendo los grandes protagonistas de la pandemia. Ellos son los que asisten a las personas que enferman y los que ejecutan medidas dirigidas a prevenir la proliferación del virus hasta que finalmente llegue a estar bajo control. Aunque en este tiempo se vienen enfrentando a un sinfín de desafíos éticos podemos identificar cuatro especialmente graves y hasta cierto punto inéditos: (A) la prestación de la asistencia en unas condiciones de falta de medios humanos y de protección personal; (B) la priorización en los recursos para la asistencia; y (C) la priorización en la distribución de las vacunas; y (D) la toma de decisiones en contexto de máxima incertidumbre.

(A) La prestación de la asistencia en unas condiciones de falta de medios humanos y de protección personal. En medio de la calamidad provocada por la pandemia, una luz ha mantenido la esperanza social en el horizonte: el comportamiento heroico de los profesionales sanitarios en todo el mundo. Cuando no había equipos de protección personal, cuando los servicios de atención primaria y los hospitales se saturaban con la afluencia incesante de personas necesitadas de asistencia, los profesionales arriesgaron sus vidas, su salud, su sosiego moral (20). Desde el punto de vista de la EpS es una doble buena noticia: porque confirma que los profesionales sanitarios son formados para anteponer los intereses del paciente sobre los suyos y porque confirma a los ciudadanos en su confianza hacia quienes cuidan de su salud.

(B) La priorización en los recursos para la asistencia. En la primera ola de la pandemia, y en menor medida en las que se han sucedido desde entonces, los recursos disponibles han sido insuficientes para atender las necesidades de las personas. La priorización en la asignación de esos recursos (en particular, respiradores y plazas de UCI) 
ha sido ineludible. Se trata de una decisión política, no científica ni clínica, que afecta directamente a los derechos de los ciudadanos, y que los profesionales sanitarios han de implementar y ejecutar (21). Sin embargo, en muchos lugares las directrices políticas no se han adoptado y han tenido que ser los sanitarios quienes fijaran los criterios de priorización: ante la pasividad política, han tenido que asumir una responsabilidad que no les correspondía. Al hacerlo, en ocasiones se ha detectado un sesgo utilitarista, de carácter capacitista (22) y edatista, que llevaba a priorizar la asistencia en función del "valor social" de la persona ${ }^{3}$ (23) y a descartar, en consecuencia, a las personas por su edad o su discapacidad. En el momento actual, esta situación sigue pendiente de solución en muchos países porque las autoridades sanitarias no han aprobado directrices claras para priorizar los recursos asistenciales.

(C) La priorización en la distribución de las vacunas. Así como la priorización en la asistencia tiene un carácter trágico (porque supone que las personas no priorizadas suelen tener una evolución infausta) la priorización en las vacunas resulta menos traumática para las personas. Además, cuando las vacunas han empezado a estar disponibles, los poderes públicos han asumido su responsabilidad y han aprobado estrategias de priorización en la vacunación. En el caso español, junto al documento base, la Estrategia está siendo actualizada con una periodicidad más o menos quincenal porque el cambio constante de circunstancias (evolución de la pandemia, número de vacunas disponibles, características de las vacunas disponibles, nuevas evidencias científicas sobre la efectividad de las vacunas, etc.) obligan a ello. Ya he hecho referencia a los principios éticos que han informado esa estrategia y que han permitido, en alguna medida, reparar el abandono que en su momento sufrieron las personas que viven (o vivían y murieron) en las residencias de mayores. Es un hecho tristemente universal, que cuando el virus se ensañó con estas personas, los sistemas sanitarios de la mayoría de los países no proporcionaron la asistencia que precisaban ${ }^{4}$.

(D) La toma de decisiones en contexto de máxima incertidumbre. Tanto la clínica y los cuidados de salud como las intervenciones de salud pública están basadas en las evidencias científicas. Los profesionales sanitarios están acostumbrados a trabajar con protocolos basados en aquellas. La pandemia ha puesto también en cuarentena este modelo

\footnotetext{
${ }^{3}$ Así denunció el Comité de Bioética de España (23).

${ }^{4}$ El caso de España, no siendo único, fue objeto de especial atención: Anmistía Internacional (24); Médicos sin fronteras (25); una aproximación sucinta a esta tragedia en el conjunto del mundo por Ortiz (26).
} 
asistencial. Se tuvo que prestar asistencia con escasa certidumbre acerca de los tratamientos disponibles. Se tuvieron que adoptar medidas de salud pública sin conocer suficientemente las características del virus o sus formas de contagio. Los políticos decían confiar en los expertos para tomar las decisiones. $\mathrm{Y}$ los expertos solicitaban marcos regulatorios claros desde los que desarrollar una actuación conforme al Derecho vigente y a los derechos humanos (27). Políticos, científicos y sanitarios se han necesitado coordinar más que nunca, aunque no siempre lo han hecho, o no lo han hecho con la suficiente trasparencia y rendición de cuentas. La participación ciudadana no ha sido promovida a través de canales idóneos para hacer llegar puntos de vista, críticas o iniciativas.

De estos cuatro desafíos éticos que han afrontado los profesionales sanitarios, se extraen algunas consecuencias para su futura EpS. La conciencia de servicio público parece asentada y no cabe más que reforzarla. Convendría estudiar si el sesgo utilitarista que se ha detectado en la asignación de recursos escasos es consecuencia de la formación recibida $\mathrm{y}$, en ese caso, valorar qué debería hacerse. Por último, la formación recibida debería incidir más en la distinción entre decisiones políticas y asistenciales, así como en los márgenes de incertidumbre con los que muchas veces hay que contar en la toma de decisiones.

\section{EpS y el derecho al acompañamiento}

Las medidas adoptadas para contener el contagio del virus SARS-CoV-2 que suponían limitación en el ejercicio de los derechos fundamentales han sido objeto de intenso debate: no solo por el procedimiento normativo empleado para aprobarlas sino también por su proporcionalidad y necesidad. En el momento más terrible de la pandemia los pacientes ingresados en los hospitales fueron privados de cualquier acompañante. En las residencias de mayores los residentes fueron confinados durante meses en sus habitaciones, sin posibilidad de recibir visitas. El daño físico, psicológico y moral de esas medidas para muchas de las personas ingresadas en los hospitales o internadas en las residencias ha sido probablemente superior al de la propia enfermedad de la COVID-19. La pandemia ha puesto de manifiesto con rotundidad no solo que la existencia biológica de cada uno está condicionada por la de los demás, sino que el aislamiento (y muy especialmente en situaciones de especial vulnerabilidad) es uno de los peores males para la salud y el bienestar de las personas.

Ante esta realidad, debería ser prioritario aprobar protocolos que garanticen que las personas ingresadas en hospitales o residencias no tengan que quedarse nunca solas o, al 
menos, con carácter continuado. Tanto el acompañamiento, como el apoyo espiritual o religioso, son derechos de las personas y manifestación elemental de humanización en la asistencia. En consecuencia, su limitación no solo deberá estar justificada ética y legalmente, sino que, además, en ningún caso deberá ser de tal intensidad que acabe, de facto, por convertirse en una absoluta privación (28).

Este derecho al acompañamiento en entornos asistenciales resulta especialmente importante para la salud y dignidad de la persona cuando se encuentra en una situación de especial vulnerabilidad: niños, personas con discapacidad y con ciertas necesidades de apoyo, personas mayores o personas que van a morir (29). No cabe pensar que la tecnología digital sea una alternativa suficiente para suplir la falta de contacto físico directo, aunque indudablemente sirva para satisfacer ciertos niveles de comunicación.

En relación con el acompañamiento, es importante hacer mención al riesgo que ha existido y sigue existiendo de que los enfermos de COVID-19 que no van a recibir tratamiento por falta de recursos o por su futilidad sean de alguna manera abandonados y no reciban tampoco cuidados paliativos. También cuando arrecia la pandemia las personas siguen teniendo derecho a morir en paz, sin sufrir y en compañía, al menos, de un ser querido. Es evidente que este derecho debe garantizarse por ley; pero deben ser los profesionales sanitarios los que, formados en el compromiso con la defensa de la dignidad de la persona y de su condición vulnerable y relacional, sean los primeros en defender ese derecho de los pacientes y en rebelarse cuando se vulnera. Es cierto que se trata de un derecho que desborda completamente el marco de exigencia estrictamente jurídico y exige un compromiso profesional, en el que la compasión y el diálogo son fundamentales (30). Pero no se debe perder de vista que el acompañamiento no es solo una práctica recomendable que los profesionales sanitarios deben promover sino un auténtico derecho que no se debe violar.

Finalmente, debemos referirnos al colectivo menos expuesto a la enfermedad y que, sin embargo, es uno de los que más está sufriendo las consecuencias de la pandemia: los niños. La pandemia les ha obligado a dejar de ir al colegio y de relacionarse con sus amigos. En un momento de la vida en que la socialización es crucial para su desarrollo se han visto recluidos en sus hogares, prácticamente aislados de sus iguales. El contacto virtual que han mantenido nos ha hecho creer que era suficiente para suplir la falta de contacto físico pero, en ocasiones, ha llegado a ser un obstáculo al florecimiento de las capacidades necesarias para la auténtica relación humana. El daño para su salud no ha venido de un virus sino del 
aislamiento (31) y, por tanto, urge adoptar medidas para que puedan normalizar su vida. Cuidar de la salud de los niños es facilitar su encuentro con los otros y en otros espacios distintos del hogar.

\section{Conclusión}

¿Cuándo, desde 1945, hemos sido tan conscientes de que nuestros actos individuales y los de nuestros gobiernos pueden determinar directamente si nosotros y nuestros seres queridos vamos a vivir o morir? (32).

La EpS en tiempos de pandemia supone redescubrir que el ser humano es relacional y vulnerable. De esta constatación se derivan algunas consecuencias que deberían informar las políticas de EpS. Primera, que los determinantes sociales de salud siguen siendo la mejor promoción de la salud. Segunda, que la salud no solo es un derecho individual sino también un deber colectivo. Tercera, que el principio de solidaridad debe informar las políticas de salud y los comportamientos individuales en relación con la salud. Cuarta, que el entorno digital, a pesar de las muchas utilidades que está mostrando en la pandemia, no es el idóneo para el desarrollo de una vida saludable. $\mathrm{Y}$, en todo caso, debe ser configurado de manera que no promueva la infodemia, ni los hábitos poco saludables. Quinta, que la distribución de recursos escasos en sanidad debe estar principalmente informada por el principio de necesidad más que por el de utilidad. Sexta, que los profesionales sanitarios deben formarse en una EpS que haya incorporado todas las lecciones que nos está dejando la pandemia. $Y$ séptima, que el aislamiento al que nos obliga la pandemia debe ser contemplado como una medida sumamente perjudicial para otros aspectos de nuestra salud y para nuestro desarrollo en general y, en consecuencia, debe ser adoptada con las máximas restricciones.

\section{Referências}

1. OMS. Promoción de la Salud: Glosario. Ginebra: OMS; 1998. Disponible en: http://apps.who.int/iris/bitstream/handle/10665/67246/WHO HPR HEP 98.1 spa.pdf;jsessi onid=CFA9328349EBB5F75F1C12F02F50C5A4? sequence=1

2. OPAS. Carta de Ottawa sobre promoción de la salud. Ottawa (Ontario), Canada:1986. Disponible en: https://www.paho.org/hq/dmdocuments/2013/Carta-de-ottawa-para-laapromocion-de-la-salud-1986-SP.pdf

3. OMS. Objetivos de Desarrollo Sostenible (ODS). Disponible en: https://www.who.int/topics/sustainable-development-goals/es/ 


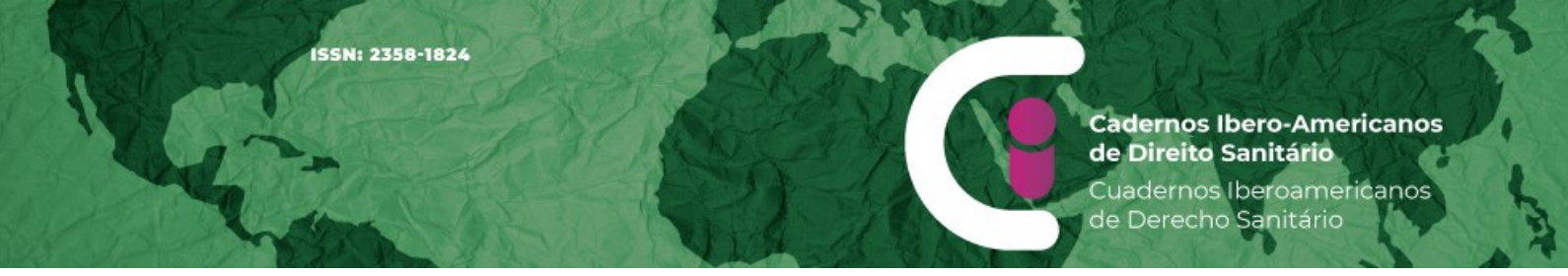

15. Bellver V. Bioética, derechos humanos y Covid-19. Cuadernos de Bioética. 2020; 31(102):167-182. doi: https://doi.org/10.30444/CB.60

16. Eri Pariser. El filtro burbuja: Cómo la web decide lo que leemos y lo que pensamos. Madrid: Taurus; 2017. 289 p.

17. Williams J. Clics contra la humanidad. Libertad y resistencia en la era de la distracción tecnológica. Barcelona: Gatopardo; 2021. 183 p.

18. Montalvo F, Bellver V. El diseño del entorno digital como presupuesto de los Derechos Digitales. Diario La Ley-Ciberderecho. 8 de marzo de 2021. Disponible en:

https://diariolaley.laleynext.es/dll/2021/03/12/el-diseno-del-entorno-digital-comopresupuesto-de-los-derechos-digitales

19. Han B-Ch. La emergencia viral y el mundo de mañana. En: Agamben G et al. Sopa de Wuhan. ASPO, 2020. Disponible en: http://iips.usac.edu.gt/wpcontent/uploads/2020/03/Sopa-de-Wuhan-ASPO.pdf

20. Bellver V. Problemas bioéticos en la prestación de los cuidados enfermeros durante la pandemia del COVID-19. Index de Enfermería. 2020;29(1-2):46-50. Disponible en:

http://ciberindex.com/index.php/ie/article/view/e12909/e12909

21. Montalvo $\mathrm{F}$, Bellver $\mathrm{V}$. Una crisis bioética dentro de la crisis sanitaria provocada por la covid-19: una reflexión sobre la priorización de pacientes en tiempos de pandemia.

Derecho y Salud. 2020;30(Extraordinario):58-73. Disponible en:

https://www.ajs.es/sites/default/files/2020-07/vol30 Extra 0205 Estudio.pdf

22. Montalvo F, Bellver V. Priorizar sin discriminar: la doctrina del Comité de Bioética de España sobre derechos de las personas con discapacidad en un contexto de pandemia. IgualdadES. 2020;3:313-341. doi: https://doi.org/10.18042/cepc/lgdES.3.02

23. Comité de Bioética de España. Informe del Comité de Bioética de España sobre los aspectos bioéticos de la priorización de recursos sanitarios en el contexto de la crisis del coronavirus. 25 de marzo de 2020. Disponible en:

http://assets.comitedebioetica.es/files/documentacion/Informe\%20CBE-

\%20Priorizacion $\% 20$ de $\% 20$ recursos $\% 20$ sanitarios-coronavirus\%20CBE.pdf

24. Anmistía Internacional. Abandonadas a su suerte. La desprotección y discriminación de las personas mayores en residencias durante la pandemia covid-19 en España. Diciembre 2020. Disponible en:

https://www.ohchr.org/Documents/Issues/OlderPersons/AgeismAgeDiscrimination/Submissi ons/NGOs/Amnesty-International-Spain.pdf

25. Médicos sin fronteras. Report: Too Little, Too Late: The unacceptable neglect of the elderly in care homes during the COVID-19 epidemic in Spain. Agosto 2020. Disponible en: https://msfcovid19.org/wp-content/uploads/2020/08/msf-report-too-little-too-late-elderly-andcovid-in-Itcf-english.pdf 
26. Ortiz I. Neglected, sacrificed: older persons during the Covid-19 pandemic. Social Europe. 5 de octubre de 2020. Disponible en: https://www.socialeurope.eu/neglectedsacrificed-older-persons-during-the-covid-19-pandemic

27. Gostin L, Friedman E, Wetter S. Responding to Covid-19: How to Navigate a Public Health Emergency Legally and Ethically. Hastings Cent Rep. 2020 Mar;50(2):8-12. doi: https://doi.org/10.1002/hast.1090.

28. Comité de Bioética de España. Declaración del Comité de Bioética de España sobre el derecho y deber de facilitar el acompañamiento y la asistencia espiritual a los pacientes con covid-19 al final de sus vidas y en situaciones de especial vulnerabilidad. Madrid, 15 de abril de 2020. Disponible en:

http://assets.comitedebioetica.es/files/documentacion/CBE Declaracion sobre acompana miento COVID19.pdf

29. Parekh de Campos A, Daniels S. Ethical Implications of COVID-19: Palliative Care, Public Health, and Long-Term Care Facilities. J Hosp Palliat Nurs. 2021 Jan 6; Publish Ahead of Print. doi: https://doi.org/10.1097/NJH.0000000000000735

30. Chochinov HM, Bolton J, Sareen J. Death, Dying, and Dignity in the Time of the COVID19 Pandemic. J Palliat Med. 2020 Oct;23(10):1294-1295. doi:

https://doi.org/10.1089/jpm.2020.0406

31. Larcher V, Brierley J. Children of COVID-19: pawns, pathfinders or partners? J Med Ethics. 2020;46(8):508-509.

32. Garton Ash T. La lección para la UE de un año de covid: 'Just do it'. El País.14 mar. 2021. Disponible en: https://www.almendron.com/tribuna/la-leccion-para-la-ue-de-un-anode-covid-just-do-it/

Capella VB. Educar para la salud en tiempos de pandemia. Cadernos Ibero-Americanos de Direito Sanitário. 2021 abr./jun.;10(2):233-252.

https://doi.org/10.17566/ciads.v10i2.787 